\title{
Inteligência: \\ o Artificial vs. o Natural
}

«... a IA (a as Ciências da Computação) podem viver e pros-
perar sem a Psicologia, mas a Psicologia não pode prosperar
sem a IA.»

A. Newell, 1981

O termo Inteligência Artificial (IA) denota para uns o estudo da inteligência/cognição como computação, para outros o desenvolvimento de uma teoria sistemática dos processos intelectuais, ou ainda a construção de máquinas capazes de realizar tarefas que exigem inteligência quando executadas pelos homens.

Raciocinar sobre os fenómenos ou as situações, presentes no nosso quotidiano, é uma das tarefas sobre as quais a IA se tem debruçado. Atrás do termo, existe uma disciplina que comunica profundamente com as Ciências da Computação, a Engenharia, a Psicologia, a Linguística e a Filosofia, mas que se distingue pelo seu objecto próprio. Por exemplo, enquanto nas ciências da Computação se escrevem programas que determinam a solução de um problema, através da mecanização da resolução manual, na IA os programas (não deterministicos) procuram a resolução, fornecendo todas as soluções possiveis. Os programas da IA são assim capazes de resolver uma classe geral de problemas. Deste modo, demonstram a sua «inteligência» através da prossecução de tarefas de grande complexidade $e$ dificuldade, como a ajuda no diagnóstico médico ou a compreensão de uma lingua natural.

Nas Ciências da Computação, os computadores sāo considerados como máquinas que manipulam números. Contrastando com este ponto de vista, na IA os computadores são encarados como máquinas que manipulam símbolos. Nas Ciências da Computação encontramos algoritmos, isto $\dot{e}$ programas que garantem que resolvem um problema ou que o resolvem dentro de certos limites de tempo. $N a I A$, os programas são heuristicos, isto $\dot{e}$, operam através de regras aproximadas, em que o conhecimento 
parcial pode ajudar à descoberta de uma solução.

O termo IA é «provocatório» por duas ordens de razões. Primeiro, porque coloca desde logo um tom pretencioso ao adjectivar o fulcro da investigação: a inteligência. Segundo, porque afasta os que embora com desejos e interesses comuns se sentem colocados de (ao) lado, em disciplinas «não inteligentes》. Uma tal «provocação» é bem nefasta para aqueles que nela trabalham, mas o termo é hoje aceite internacionalmente.

A disciplina IA está em franco crescimento. Nas Universidades a disciplina está inscrita em variadas licenciaturas, e existem muitos departamentos que apoiam os trabalhos de investigação que poderão conduzir a teses de doutoramento. Organizações industriais (por exemplo, a IBM, a DEC, a UNIVAC, a XEROX, e a Schulumberger) aplicam as ideias da $I A$ às tecnologias de fabrico $e$ a actividades de engenharia. As organizações comerciais surgem nos EUA, no Reino Unido e na França, vendendo microcomputadores, sistemas para o diagnóstico médico, para a determinação de estruturas químicas e para a avaliação de depósitos de minerais, robôs, ou subprodutos como aparelhos para processamento de imagens (visão computacional). Existem associações nacionais $e$ internacionais, monografias, revistas cientificas e jornais, e reuniōes nacionais e internacionais regulares. Em suma, a $I A$ ao longo de 28 anos de existência passou de arte para ciência aplicada.

Disciplinas como a Psicologia, a Linguística e a Filosofia têm sofrido uma forte influência pelos estudos conduzidos dentro da IA sobre os processos cognitivos, que estầo envolvidos no raciocínio e no planeamento. As teorias têm sido confrontadas e as novas metodologias têm sido ensaiadas levando à produção de novos conhecimentos sobre os fenómenos psicológicos e linguisticos, e os fenómenos associados ao conhecimento do senso corrente (causalidade, crenças). O mesmo se poderá dizer da Ciência dos Computadores, cujo objectivo, associado à realização de tarefas ao serviço do homem, tem sido enriquecido pelos estudos realizados em IA em direcção à mecanização da inteligência. Um bom exemplo pode-se encontrar no programa japonês que visa produzir os computadores da $5^{a}$ geração, capazes de processar o conhecimento, no fim da presente década.

Ao abrir este número da revista dedicado à $I A$, mas curiosamente intitulado «Inteligência: o artificial versus o natural», gostaria de abordar a sua contradiçāo aparente. De facto, no dia-a-dia encontramos objectos e fenómenos em que o natural e o artificial estão intimamente associados. Uma seara é um artefacto criado pelo homem, e o cereal plantado näo passa de um artefacto genético. Contudo, as leis da biologia aplicam-se às searas e aos cereais. Um aparelho de TV é um artefacto, mas o seu funcionamento (transmissão e recepção) é regulado pelas equaçôes de Maxwell. Não existe qualquer contradiçāo em aplicarmos os métodos e as descobertas das Ciências Naturais aos objectos artificiais. As profissóes da engenha- 
ria agronómica e electrónica são disso exemplo. Do mesmo modo o faz a Psicologia ao abordar os fenómenos naturais, como o comportamento, a cognição e a aprendizagem. A IA ao ensaiar compreender a simular/replicar tais fenómenos em sistemas computacionais (programas e equipamentos) mais não faz do que aprender com a Psicologia. Mas, os conceitos inventados na IA, no processo de construir máquinas inteligentes, permitiu aos psicólogos construir, por seu lado, modelos mais poderosos com os quais explicaram a inteligência humana e animal.

$O$ comportamento humano é um fenómeno artificial, e a artificialidade pode também ser encontrada no pensamento humano. Vejamos o caso da rotina de um engenheiro. Diariamente ele é obrigado a ultrapassar os limites do seu «equipamento» de processamento de informação. E consegue isso aprendendo a usar aquele «equipamento» de modo mais eficiente: descobrindo e adoptando mais estratégias eficientes para levar a cabo as suas tarefas de pensamento.

Não existe ainda unanimidade dentro da IA sobre o que ela é, eo que ela deverá/deveria ser! Assim, enquanto uns pretendem estudar a inteligência humana através da criação de inteligência artificial (Simon, 1981; Newell, 1981), outros defendem a construçäo de sistemas periciais capazes de actuarem como consultores dos especialistas (por exemplo, no diagnóstico médico). De um lado, colocam-se os que pretendem abordar os fenómenos psicológicos através de outros instrumentos, e do outro lado, os que querem transformar a IA num empreendimento de engenharia cujo objectivo é sintetizar artefactos inteligentes. Entre estes extremos, existe um vasto campo de trabalho, compartimentado em diversas áreas interdependentes, tais como: a resolução de quebra-cabeças, a demonstração de teoremas, a dedução automática, a aprendizagem, a compreensão $e$ geração da lingua natural, a sintese de planos, o diagnóstico médico, isío é: territórios de tarefas exigindo amplos requisitos intelectuais.

Ao longo da história da IA abundam as teorias propostas e as metodologias de investigação. Independentemente do valor instrinseco de algumas ideias teóricas, sobressaiem várias inovações metodológicas, em particular o recurso sistemático aos programas de computador, ao projecto de programas e às linguagens de programação como veiculos experimentais.

$O$ debate tem sido fértil e os resultados intelectuais brotaram quase sempre da resoluçäo de dicotomias. Eis uma lista dessas dicotomias apresentada por Newell em 1982:

1640-1945 - Mecanismo versus Teleologia: resolvida com a criação da Cibernética;

1800-1920-Biologia Natural versus Vitalismo: estabeleceu o corpo como uma máquina; 
1870- -Razāo versus Emoçāo e Sentimento 1: separou as máquinas dos homens;

1870-1970-Lógico versus Psicológico: separou a Lógica da Psicologia;

1940-1970 - Analógico versus Digital: criou a Ciência dos Computadores;

1955-1965 - Símbolos versus Números: isolou a IA dentro da Ciência dos Computadores;

1955- - Simbólico versus Sistemas Contínuos: separou a IA da Cibernética;

1955-1965 - Resoluçāo de Problemas versus Reconhecimento 1: separou a IA do Reconhecimento de Padrōes;

1955-1965-Série versus Paralelo 1: coordenado com os últimos quatro resultados;

1955-1965-Heuristicas versus Algoritmos: isolou a IA dentro da Ciência dos Computadores;

1955-1965 -Interpretaçẩo versus Compilaçāo: isolou a IA dentro da Ciência dos Computadores;

1955- -Simulaçāo versus Análise de Engenharia: dividiu a IA;

1960- -Substituiçẫo versus Ajuda a humanos: isolou a IA;

1960- -Epistemologia versus Heuristica: dividiu a IA;

1965-1980-Procura versus Conhecimento: desvio paradigmático dentro da IA;

1965-1975-Poder versus Generalidade: desvio de tarefas de interesse;

1965- -Competência versus Desempenho: separou a Linguística da IA e da Psicologia;

1965-1975-Memória versus Processamento: separou a Psicologia Cognitiva da IA; 
1965-1975-Resolução de problemas versus Reconhecimento 2: o Reconhecimento volta à IA via a Robótica;

1965-1975 - Sintaxe versus Semântica: separou a Linguística da IA;

1965- -Demonstração de Teoremas versus Resolução de Problemas: dividiu a IA;

1965- -Engenharia versus Ciência: dividiu a Ciência dos Computadores, incluindo a $I A$;

1970-1980-Linguagem versus Tarefas: a lingua natural tornou-se central;

1977-1980 - Representação Procedimental versus Declarativa: desvio da Demonstração de Teoremas;

1970-1980-Esqueletos versus Atomos: desvio para as representações globais;

1970- -Razão versus Emoção e Sentimento 2: separou a IA da Filosofia do pensamento;

1975- - Brinquedos versus Tarefas Reais: desvio para as aplicações;

1975- - Série versus Paralelo 2: apareceu a IA distribuida;

1975- - Desempenhamento versus Aprendizagem;

1975- - Psicologia versus Neurologia: nova ligação à Neurologia;

1980- -Série versus Paralelo 3: nova tentativa nos sistemas neurológicos;

1980- -Resolução de Problemas versus Reconhecimento 3: regresso da Robótica;

1980- -Representação Procedimental versus Declarativa 2: Prolog. 
No presente número não houve a pretensão de uma abordagem exaustiva da IA, nem tão-pouco se optou por uma colectânea de artigos de investigação. Quisemos, antes sim, divulgar a IA que poderia «tocar» os leitores da revista, e para isso convidámos alguns profissionais que trabalham em Portugal para ensaiarem abordagens despretenciosas a alguns dos dominios da IA.

\section{HELDER COELHO}

Centro de Informática, Laboratório Nacional de Engenharia Civil 